\title{
Incidence of Caecal Coccidiosis in Adult Layer Chicken
}

\author{
M. Lakshmi Namratha, K.B. Ashok Kumar Reddy, Y. Ravi Kumar*, \\ K. Sandhyarani and M. Lakshman \\ Department of Veterinary Pathology, C.V.Sc, P.V.N.R.T.V.U, Hyderabad, \\ Telangana, India \\ *Corresponding author
}

\begin{tabular}{|c|c|}
\hline & A B S T R A C T \\
\hline $\begin{array}{l}\text { Ke y w o r d s } \\
\text { Rajasri, Caecal } \\
\text { coccidiosis, } \\
\text { Haemorrhagic } \\
\text { enteritis, Coccidial } \\
\text { oocyst }\end{array}$ & \multirow{3}{*}{$\begin{array}{l}\text { Caecal coccidiosis was diagnosed in Rajasri birds of nineteen weeks age presented } \\
\text { for routine postmortem examination at Department of Veterinary Pathology, } \\
\text { College of Veterinary Science, Hyderabad. Clinically birds showed inappetence, } \\
\text { depression, ruffled feathers, bloody diarrhea, anemia and mortality of about } 21 \\
\text { birds out of } 65 \text { birds }(32.3 \%) \text { for a period of two weeks. Grossly, extremely } \\
\text { ballooned caeca, white necrotic foci visible from outside of caeca, haemorrhagic } \\
\text { enteritis, watery ingesta mixed with mucus and blood were observed. Upon } \\
\text { opening of the caeca, semi liquid bloody mass was observed and liver was pale. } \\
\text { Faecal smear examination revealed coccidial oocyst. Histopathological } \\
\text { examination of caecum revealed coccidian lifecycle stages with destruction of } \\
\text { different layers of the caecum. }\end{array}$} \\
\hline Article & \\
\hline $\begin{array}{l}\text { Accepted: } \\
\text { 04 August } 2019 \\
\text { Available Online: } \\
\text { 10 September } 2019\end{array}$ & \\
\hline
\end{tabular}

\section{Introduction}

Coccidiosis one of the most economically important parasitic diseases in poultry in modern poultry production especially in litters. Coccidiosis is caused by species of intracellular protozoan parasites belonging to the genus Eimeria (Phylum Apicomplexa) (Shirley, 1995). It causes high mortality in young chicks between the age of 3 and 18 weeks (Nematollahi et al, 2009). Despite of advances made in the field of diagnosis in prevention, treatment and control through managemental and nutritional practices, avian coccidiosis remains one of the major diseases in chicken (Sawale el al., 2018). Economic losses to the poultry industry is due to high morbidity and mortality. Infection is transmitted through horizontal course by ingestion of coccidial oocyst contaminated feed and water. Bad management (such as wet litter that encourages oocyst sporulation, contaminated drinkers and feeders, bad ventilation, and high stocking density) can exacerbate the clinical signs (Ruff, 1993). The short, direct life cycle and high reproductive potential of coccidial organisms in poultry often leads to severe outbreaks of the disease 
in small backyard flocks or in the modern poultry house (McDougald and Fitz-Coy, 2008).

Avian coccidiosis is classified into caecal and intestinal forms. Caecal coccidiosis is an acute disease caused by Eimeria tenella characterised by bloody droppings and anemia (Whitmarsh, 1997). Clinical signs include dysentery, enteritis, emaciation, drooping wings, poor growth and low production. Grossly, caecum appears to be enlarged with clotted blood, haemorrhagic spots on caecal wall, inflammation, necrotic patches and dilation of caecum with consolidation of caecal contents (Adamu et la., 2013 and Sharma et al., 2015).

Microscopically, disruption of caecal mucosa, clusters of oocysts, marked haemorrhage, necrosis of caecal mucosa and massive infiltration by heterophils and mononuclear cells (MNC) are characteristic (Amer et al., 2010). The present paper discusses an incidence of caecal coccidiosis in Rajasri birds of nineteen weeks age. A detailed gross and microscopic examination was discussed.

\section{Materials and Methods}

A sudden mortality in ninteen weeks old Rajasri birds was reported at Poultry Research Station (PRS) Rajendranagar, College of Veterinary Science, Hyderabad. Caecal coccidiosis was diagnosed in 21 out of 65 birds evaluated for a period of two weeks. Faecal smears from caecum were prepared by adding a small quantity of faeces on a clean microscope slide, mixed with a few drops of water thoroughly and covered with coverslip and examined under microscope.

Intestine slices $\left(1 \times 1 \mathrm{~cm}^{3}\right)$ were collected and fixed in $10 \%$ neutral buffered formalin (NBF) soon after necropsy. The samples were processed, sectioned $(5 \mu \mathrm{m})$ and stained with Haematoxylin and Eosin (H\&E) for histopathological examination as per the standard procedure (Luna, 1968)

\section{Results and Discussion}

Caecal coccidiosis was diagnosed in 21 out of 65 birds presented for routine necropsy examination in a period of two weeks. Clinically birds showed in appetence, depression, ruffled feathers, bloody diarrhea and anemia.Gross examination revealed extremely ballooned caeca, severe haemorrhages on the caecal mucosa, watery ingesta mixed with mucus and blood and haemorrhagic enteritis was seen (Fig. 1). Upon opening of the caeca, bloody mass was noticed and severe haemorrhages on the caecal mucosa were prominent (Fig. 2) and liver was found to be pale with rounded edges (Fig. 3). Eimeria tenella is easily identified by its predilection site (caeca). Faecal smear examination revealed presence of unsporulated ovoid oocysts of coccidia (Fig. 4). Histopathology of caecum revealed severe destruction of different layers of the caecum with desquamation of enterocytes, presence of oocysts and schizont stages in the submucosa with massive mononuclear cell infiltration (Fig. 5).

Caecal coccidiosis was diagnosed through demonstration of postmortem changes recorded in dead birds. The gross and necropsy changes revealed extremely ballooned caecum, haemorrhages, necrotic patches and dilation of caecum with consolidation of caecal contents. Pale liver and anemia could be due to extensive blood loss. Similar gross lesions of caecal coccidiosis in chicken were reported by Adamu et al., (2013) and Sharma et al., (2015). Faecal smear examination revealed numerous oocysts of Eimeria tenella and histopathological findings showed presence of oocysts and shizont stages in the submucosa which were in accordance with the findings of Amer et al., (2010) and Adamu et la., (2013). 


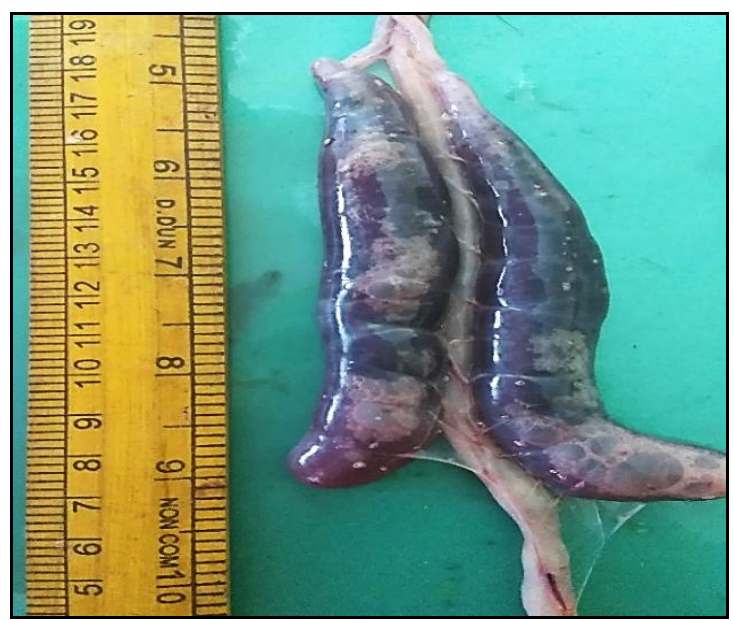

Fig.1 Ballooned caeca with watery contents mixed with blood and mucus

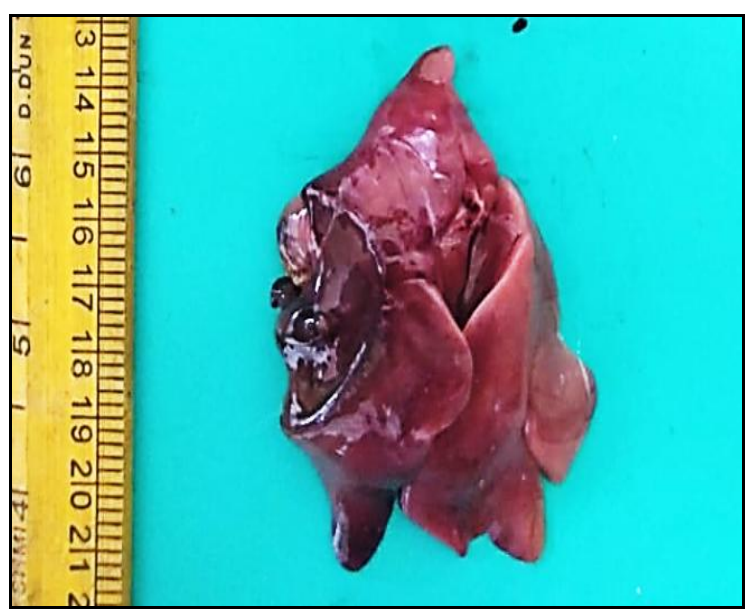

Fig.3 Pale liver with rounded edges

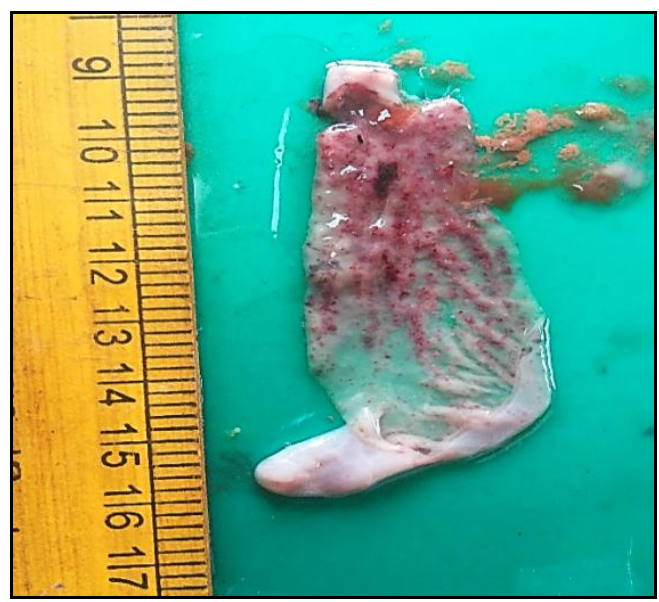

Fig.2 Severe haemorrhages on the caecal mucosa

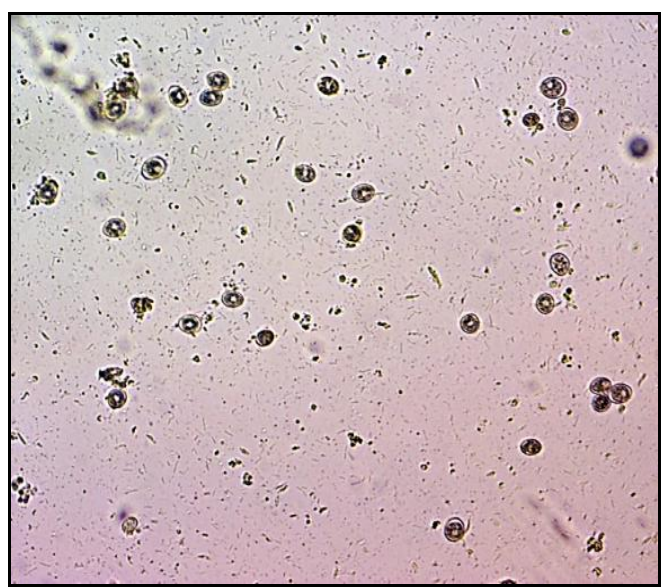

Fig.4 Faecal smear examination showing numerous unsporulated ovoid oocysts of coccidia $\mathrm{x} 100$

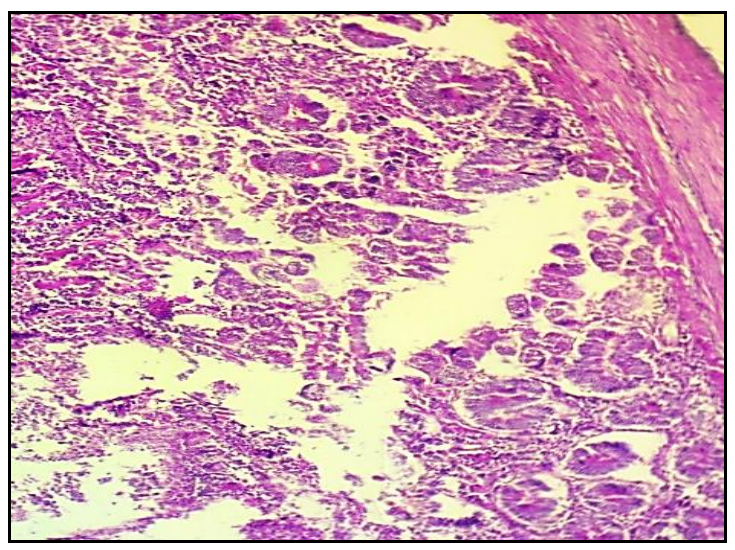

Fig.5 Destruction of different layers of caecum with desquamation of enterocytes,presence of oocysts and schizont stages in thesubmucosa and massive mononuclear cell infiltration

$(\mathrm{H} \& \mathrm{E} \times 100)$ 


\section{Acknowledgement}

Authors are thankful to PV Narsimha Rao Telangana Veterinary University, Rajendranagar for providing necessary facility to carry out the investigation.

\section{References}

Adamu M, Boonkaewwan C, Gongruttananun $\mathrm{N}$, Vongpakorn M. Hematological, biochemical and histopathological changes caused by coccidiosis in chickens. Kasetsart J. 2013; 47(3):238-46.

Amer MM, Awaad MH, El-Khateeb RM, Abu-Elezz NM, Sherein-Said A, Ghetas MM, Kutkat MA. Isolation and identification of Eimeria from field coccidiosis in chickens. Journal of American Science. 2010; 6(10):110714.

Luna, GLHT. Manual of histological and special staining techniques. $2^{\text {nd }}$ ed: The Blakistone Division McGraw-Hill Book Company, Inc. New York, Toronto London 1968: 1-5:9-34.

McDougald, LR. and Fitz-Coy, SH. Protozoal infection, 2008; pp. 1068-1080. In Y.M. Saif, Disease of Poultry. 12th ed. Blackwell Publishing. Ames, IA, USA.

Nematollahi A, Moghaddam G and Pourabad
RF. Prevalence of Eimeria species among broiler chicks in Tabriz (Northwest of Iran). Mun. Ent. Zool. 2009;4 (1): 53-58.

Ruff MD. External and internal factors affecting the severity of avian coccidiosis. In: Proceedings of the Sixth International Coccidiosis Conference, 1993; 21-25:73-79.

Sawale, G. K., Rambabu, D., Kommu, S., Bhandurge, M., Naik, R., \& Lakshman, M. (2018). Outbreak of Intestinal Coccidiosis Due to Eimeria Necatrix in Rajasri Birds: PathoMorphological and Electron Microscopic Study. International Journal of Livestock Research, 8(12), 247-251.

Sharma S, Azmi S, Iqbal A, Nasirudullah N and Mushtaq I. Pathomorphological alterations associated with chicken coccidiosis in Jammu division of India. J Parasit Dis. 2015; 39 (2):14751.

Shirley MW. Eimeria species and strains of chickens. Guidelines on techniques in coccidiosis research. 1995:1-25.

Whitmarsh S. Protozoan Poultry Diseases. Poultry Science Home page, College of Agricultural and Life Sciences, Mississippi State University. http://www.misstate.edu/dept/poultry/ disproto.Htm.1997.

\section{How to cite this article:}

Lakshmi Namratha, M., K.B. Ashok Kumar Reddy, Y. Ravi Kumar, K. Sandhyarani and Lakshman, M. 2019. Incidence of Caecal Coccidiosis in Adult Layer Chicken. Int.J.Curr.Microbiol.App.Sci. 8(09): 577-580. doi: https://doi.org/10.20546/ijcmas.2019.809.069 